\title{
Design thinking: un enfoque educativo en el aula de segundas lenguas en la era pos-COVID
}

\author{
Manuela Mena Octavio \\ Directora académica de The Language House/Fundadora de feelthelanguage.com/ \\ Profesora en la Universidad Nebrija y en SDI Múnich \\ mmena30@gmail.com | https://orcid.org/0000-0002-6937-2959
}

Este trabajo ha obtenido un Accésit del Premio Estudios Financieros 2020 en la modalidad de Educación y Nuevas Tecnologías.

El jurado ha estado compuesto por: don Manuel Area Moreira, doña Eva María Bailén Fernández, don Julio Cabero Almenara, doña Ana García-Valcárcel Muñoz-Repiso, don Pedro José González Felipe y don Alfonso Gutiérrez Martín.

Los trabajos se presentan con seudónimo y la selección se efectúa garantizando el anonimato de los autores.

\section{Extracto}

El nuevo escenario que se abre en las aulas de los centros educativos de nuestro país con la llegada de la era pos-COVID podría suponer la palanca de cambio definitiva para modificar las arcaicas estructuras sobre las que se asienta nuestro sistema educativo actual. En este nuevo contexto hay dos elementos que van a desempeñar un papel crucial: la empatía y la tecnología. El presente trabajo de investigación tiene como objetivo justificar la necesidad de implementar un enfoque como el design thinking (DT) dentro del modelo de enseñanza-aprendizaje en remoto. Asimismo, se presenta una experiencia de innovación educativa para el aula en línea de lengua extranjera con estudiantes de secundaria a fin de fomentar la empatía, la competencia digital y el aprendizaje colaborativo a partir del desarrollo de tareas significativas en remoto.

Palabras clave: design thinking (DT); empatía; competencia digital; enseñanza en línea; e-learning; aprendizaje de segundas lenguas; COVID. en la era pos-COVID. Tecnología, Ciencia y Educación, 18, 45-75. 


\title{
Design thinking: an educational approach in the second language classroom in the post-COVID era
}

\author{
Manuela Mena Octavio
}

\begin{abstract}
The new scenario that is opening up in the classrooms of our country with the arrival of the post-COVID era could be the definitive lever for change to modify the archaic structures on which our current educational system is based. In this new context there are two elements that will play a crucial role: empathy and technology.

This research work aims to justify the need to implement an approach like design thinking (DT) within the remote teaching-learning model. It also presents an innovative educational experience for the online foreign language classroom with high school students with the purpose of promoting empathy, digital competence and collaborative learning by carrying out meaningful online tasks.
\end{abstract}

Keywords: design thinking (DT); empathy; digital competence; online teaching; e-learning; second language learning; COVID. 


\section{Sumario}

1. Justificación

2. Fundamentación teórica

2.1. Breve aproximación al DT

2.2. El DT y el MM

2.3. El DT en las aulas

2.4. Las cinco etapas del DT

3. Los beneficios del DT en el aula de segundas lenguas

4. La competencia digital en el sistema educativo español: una mirada crítica

5. La enseñanza a distancia en el sistema educativo español

6. Diseño de un proyecto de innovación educativa a distancia para el aula de idiomas a través del DT

6.1. Objetivos específicos del proyecto de innovación

6.2. Objetivos específicos de área y comunes a todas las propuestas

6.3. Descripción del grupo meta

6.4. Metodología

6.5. Evaluación del diseño de innovación

7. Conclusiones

8. Implicaciones futuras para la comunidad educativa

Referencias bibliográficas 


\section{Justificación}

Si bien en la última década se ha hablado mucho de la existencia de una generación «nativa digital» cuyo futuro educativo se encontraba inexorablemente vinculado al avance imparable de la tecnología, la falta de una competencia digital real y efectiva dentro de las aulas ha quedado patente cuando el modelo tradicional de clase presencial se ha visto sustituido por un modelo de enseñanza en línea «de emergencia».

Además de la limitada formación en el uso de las herramientas digitales por parte del profesorado y del alumnado, la existencia de una tremenda brecha digital por todo el territorio nacional ha puesto de manifiesto las carencias y puntos débiles de un sistema que no parece estar preparado para dar respuesta a las necesidades cambiantes de una sociedad interconectada, vulnerable y en constante metamorfosis.

Ante el nuevo escenario que se abre, resulta imperativo apostar por modelos y enfoques educativos flexibles, capaces de desarrollar en las nuevas generaciones de aprendientes cualidades de suma importancia, como la empatía, el emprendimiento o la capacidad para innovar a partir del uso eficiente de herramientas digitales actuales y verdaderamente transformadoras para, de esta forma, poder dar respuesta a las nuevas demandas y exigencias sociales, educativas, económicas, emocionales y tecnológicas.

\section{Resulta imperativo apostar por modelos y enfoques educativos flexibles, capaces de desarrollar en las nuevas generaciones de aprendientes cualidades de suma importancia, como la empatía, el emprendimiento o la capacidad para innovar a partir del uso eficiente de herramientas digitales actuales y verdaderamente transformadoras}

\section{Fundamentación teórica}

\subsection{Breve aproximación al DT}

De un tiempo a esta parte, el término «DT» está resonando con fuerza en diferentes ámbitos, como el empresarial y el educativo, gracias a la inestimable labor de difusión que están haciendo revistas de prestigio como Forbes o Harvard Business Review, en las cuales numerosos expertos de diferentes ámbitos hablan del DT como una herramienta esencial para la humanización y la innovación. 
Sin embargo, y aunque ha sido en los últimos años cuando más se ha empezado a hablar de este enfoque, también conocido en español como «pensamiento de diseño», existen numerosos artículos, como el publicado por Szczepanska (2017), que sitúan sus orígenes a comienzos de los años sesenta, vinculándolo con la aparición del modelo de diseño cooperativo escandinavo basado en el trabajo desarrollado por Buckminster Fuller (1959), quien introdujo el concepto de los «equipos de trabajo multidisciplinares» y confirió un enfoque más científico y sistematizado al proceso de diseño.

Recientemente, el DT ha sido popularizado por el profesor Tim Brown, miembro de la Universidad de Stanford, quien habla de él como una herramienta que nació con el objetivo de ayudar a empresas y organizaciones de todo el mundo a resolver problemáticas de diversa índole y a favorecer la innovación a través de la implementación de diferentes procesos creativos. La premisa fundamental de la que parte el DT es que adoptar los procesos de pensamiento de un diseñador puede transformar significativamente la manera en la que las organizaciones desarrollan sus productos, servicios y estrategias, haciéndolas más innovadoras, humanizadas y transformadoras. De acuerdo con David Kelley, fundador de d.school (Standford Design Institute), para que el enfoque del DT pueda funcionar correctamente se han de tener en cuenta las siguientes consideraciones generales:

- Trabajar desde la empatía. Partir de la empatía es vital para poder identificar posibles problemáticas o mejoras y diseñar en función de una necesidad real. En este sentido, la fase inicial que se incluye en el proceso de DT, y que se detalla en el siguiente apartado, es lo que diferencia los procesos basados en el pensamiento de diseño de aquellos fundamentados en un pensamiento más puramente académico (Brown, 2009).

- Atención plena y consciente. Cada uno de los pasos que conforman el proceso del DT cuenta con unos propósitos, unos objetivos y unas estrategias concretas. Prestar atención plena y consciente a cada uno de los elementos anteriormente mencionados, en cada una de las etapas del proceso, es esencial para asegurar el éxito.

- Experimentar y prototipar. Dos ingredientes esenciales en el proceso de DT son la exploración y la experimentación. La creación de un prototipo, ya sea este un producto o un servicio, permite al diseñador observar cuál puede ser el comportamiento y la reacción del usuario frente al producto final y recibir así retroalimentación de utilidad para mejorar su diseño.

- Orientarse a la acción. Durante todo el proceso, el diseñador debe estar preparado para tomar decisiones, experimentar y probar el producto o servicio tantas veces como sean necesarias. En un contexto de testeo constante es muy

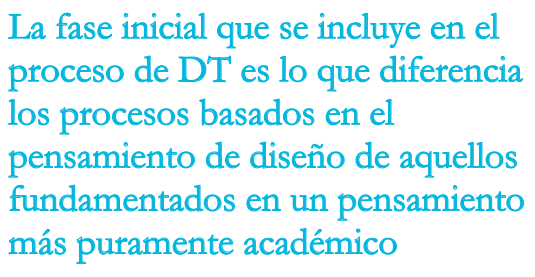

La fase inicial que se incluye en el proceso de D'T es lo que diferencia los procesos basados en el pensamiento de diseño de aquellos fundamentados en un pensamente académico
más 
probable que aparezcan errores. Ante esta situación, el diseñador debe aprender a asimilarlos como parte natural del proceso y a probar soluciones alternativas hasta conseguir el resultado deseado.

Superar el miedo y abrazar el error permite al diseñador ser más creativo, generar más ideas y no sentir temor a probar soluciones novedosas. Un comportamiento orientado a la acción requiere que el diseñador sea consciente de que el error no es el resultado, sino parte intrínseca del proceso, y que, a través de varias iteraciones, el prototipo inicial se irá transformando en el producto o solución deseada.

- Mostrar en lugar de contar. A la hora de presentar las ideas, es imprescindible que el diseñador recurra a mapas conceptuales, sketches o prototipos tangibles. Compartir una idea o concepto abstracto empleando representaciones visuales concretas favorecerá la comprensión de la intención comunicativa (Arnheim, 1969).

- Colaborar. Los individuos con mentalidad colaborativa son capaces de aprender y trabajar en equipo empleando sus habilidades sociales e interpersonales para conseguir un objetivo común. Un conjunto de perspectivas, habilidades y estilos de aprendizajes diferentes es sinónimo de soluciones innovadoras y creativas. El diseñador ha de ser capaz de aplicar su empatía y regular sus emociones para poder contribuir a la creación de un buen clima de trabajo. Además, valorar el trabajo de los demás miembros del equipo ayuda a minimizar la posibilidad de que surjan relaciones jerárquicas y de abuso de poder. Al mismo tiempo, reducir la competición entre los miembros contribuye a la mejoría de las relaciones interpersonales y al incremento de la motivación en el entorno laboral o de aprendizaje.

\subsection{EI DT y el MM}

Hablar de DT es hablar del movimiento Maker (MM) en educación. Su impulsor, Dale Dougherty, creó en 2005 las Maker Faires y la revista Make, dos proyectos pensados para dar visibilidad a los proyectos DIY (do it yourself). En su charla TED de 2011, Dougherty explica que «todos somos hacedores, nacimos hacedores, tenemos esa habilidad de hacer cosas, de agarrar las cosas con nuestras manos».

La educación Maker es un enfoque de construcción del aprendizaje que surge a partir de la elaboración y la creación de objetos y proyectos. Los contenidos de aprendizaje de 
una o más materias se construyen en la mente del aprendiente a través de la experimentación con materiales y herramientas. Este enfoque busca crear actividades personalmente significativas, que expresen visiones artísticas, usando tecnología y aplicando conceptos científicos.

Derivado del DT, el MM es la materialización teórica y física del constructivismo. EI DT y el MM se complementan a la perfección en el sentido de que el DT supone el marco en el cual se desarrolla todo el proceso de creación.
Los contenidos de aprendizaje de una o más materias se construyen en la mente del aprendiente a través de la experimentación con materiales y herramientas. Este enfoque busca crear actividades personalmente significativas, que expresen visiones artísticas, usando tecnología y aplicando conceptos científicos

La transformación educativa que supone la implementación de un enfoque como el DT a través de la materialización del MM tiene, entre otros muchos efectos positivos, convertir a los estudiantes en auténticos prosumidores ${ }^{1}$, agentes encargados de dirigir su propio aprendizaje, así como el desarrollo del pensamiento creativo (Robinson y Aronica, 2015), una de las habilidades clave que busca fomentar la nueva escuela del siglo XXI. Asimismo, los aprendientes desarrollan hábitos de la mente o conductas intelectuales que les permitirán resolver problemas de la vida diaria, tomar decisiones adecuadas o enfrentarse a las incertidumbres de la sociedad de conocimientos múltiples, pues, como dice Morin (1999): «Aprender hoy es dialogar con la incertidumbre» (p. 71).

\subsection{EI DT en las aulas}

Como se presenta en el extracto y en la justificación del presente trabajo, vivimos en una sociedad en constante cambio y en la que aparecen nuevos retos y problemáticas a cada instante. Debido a estos vertiginosos cambios, la manera en la que desarrollamos nuestros trabajos también se está viendo alterada. Sin embargo, y pese a estos reajustes constantes en la esfera profesional, el modelo de enseñanza y aprendizaje que se impone en la mayoría de los centros educativos de nuestro país permanece inmutable, provocando un importante desfase entre la realidad educativa y las necesidades apremiantes de un mercado laboral cada vez más impredecible, interconectado y tecnológico.

1 «Prosumidor» es un término formado en español a partir de «productor» (o «profesional» o «proveedor») y «consumidor», y que puede sustituir al anglicismo prosumer. En economía se emplea para referirse a la persona que, por tener un conocimiento de nivel especializado, es tanto usuario de un bien o servicio, por ejemplo, noticias, como productor o fabricante del mismo, gracias a mecanismos como internet, que rompen la nítida distinción tradicional entre consumidor y productor. 
Según David H. Autor, profesor de economía en el Massachusetts Institute of Technology (MIT), las tareas laborales pueden dividirse en rutinarias y no rutinarias. Las rutinarias consisten en interiorizar y llevar a cabo procedimientos repetitivos, mientras que las no rutinarias consisten en la realización de actividades y tareas abstractas que requieren de una mayor intuición y creatividad. En su estudio de 2003, Autor destaca que, en países desarrollados como EE. UU., las profesiones basadas en la realización de tareas rutinarias han disminuido drásticamente en los últimos treinta años, mientras que, por el contrario, aquellos trabajos más analíticos y que requieren de habilidades interpersonales, así como de una mayor capacidad de adaptación y flexibilidad mental, han crecido de manera exponencial.

En vista de los datos arrojados por el estudio de Autor-contrastados estos con los ofrecidos por el Banco Mundial-, así como por las estadísticas publicadas por la Confederación Española de Organizaciones Empresariales (CEOE) en el Plan Digital 2020 de digitalización de la sociedad española -sobre el preocupante porcentaje de jóvenes (15-29 años) que han abandonado el sistema educativo, no participan en ninguna acción formativa, carecen de empleo o no lo buscan activamente desde la crisis de 2008-, se torna imperativo que los educadores se adapten a las nuevas demandas y exigencias del mercado laboral contemporáneo y ofrezcan a los discentes experiencias de aprendizaje significativas y motivadoras, basadas en tareas no rutinarias que favorezcan el desarrollo de un tipo de pensamiento más creativo y, sobre todo, que acerquen la realidad educativa a la realidad del mercado laboral.

En este sentido, Lee (2018) propone el enfoque del DT como una alternativa para el aula, capaz de ofrecer a los estudiantes contextos de aprendizaje en los que desarrollar habilidades que estén más en consonancia con las exigencias de la sociedad actual. Según este autor, las habilidades que todo docente debe procurar desarrollar en sus estudiantes podrían resumirse en siete:
Lee (2018) propone el enfoque del DT como una alternativa para el aula, capaz de ofrecer a los estudiantes contextos de aprendizaje en los que desarrollar habilidades que estén más en consonancia con las exigencias de la sociedad actual

- Pensamiento crítico para la resolución de problemas.

- Colaboración.

- Adaptación.

- Iniciativa y emprendimiento.

- Comunicación efectiva.

- Capacidad para analizar y evaluar la información.

- Imaginación. 
Además de favorecer el desarrollo de las siete habilidades anteriormente mencionadas, el DT permite cultivar la mentalidad de crecimiento y otras destrezas fundamentales para convertirse en trabajadores de éxito, en ciudadanos responsables y en aprendientes curiosos. Incorporar el enfoque del DT en las aulas ayudará a los alumnos a acercarse a los problemas de una manera más innovadora, creativa, eficiente, humana y empática. Cabe aquí señalar la gran similitud existente entre las habilidades para la supervivencia propuestas por Lee (véase columna izqda. del cuadro 1) y las competencias clave estipuladas y recogidas en el currículo educativo español (véase columna dcha. del cuadro 1).

Cuadro 1. Correspondencia entre las habilidades desarrolladas a través del DT y las competencias educativas clave

Habilidades desarrolladas a través del DT

Pensamiento crítico para la resolución de problemas.

Iniciativa y emprendimiento.

Comunicación efectiva.
Competencias educativas clave
Competencia de sentido de iniciativa y espíritu emprendedor.

Capacidad para analizar y evaluar la información.

Competencia de comunicación lingüística.

Competencia de aprender a aprender.

Fuente: elaboración propia.

A través del enfoque del DT, los estudiantes se involucran en procesos de búsqueda y análisis de información e investigación activa. El hecho de acceder a diferentes fuentes les ayuda a familiarizarse con las principales características de las diferentes tipologías textuales. Además de trabajar la comprensión lectora, el acceso a otros contenidos multimodales les ayuda a desarrollar una capacidad crítica para discernir la información principal, relevante y fiable de la secundaria y no veraz.

El proceso que caracteriza al DT permite a los estudiantes seleccionar el tema objeto de estudio y análisis, el cual, en la mayoría de los casos, se trata de una necesidad real detectada en la comunidad más inmediata. Este marco ofrece una excelente oportunidad para el desarrollo de una cualidad clave y fundamental como es la empatía y que en entornos virtuales de aprendizaje apenas se desarrolla debido a la falta de componentes como el afectivo, el emocional o el social, que sí suelen estar presentes en el aula presencial. Durante todo el proceso, los estudiantes han de llevar a cabo miniprocesos de investigación y una 
búsqueda activa de información. Al término del proceso, los estudiantes habrán adquirido un conocimiento profundo y exhaustivo del tema objeto de estudio y habrán desarrollado las capacidades y habilidades necesarias para poder aplicar todo ese nuevo conocimiento a su vida real y entorno más directo con un impacto muy positivo.

La colaboración e interacción entre iguales son fundamentales durante el proceso de diseño. Desde el planteamiento de la problemática hasta la presentación de las posibles soluciones, los estudiantes trabajan, colaboran y cooperan para poder sacar adelante el diseño en todas sus fases. Gracias a este contexto, los discentes adquieren experiencia de primera mano sobre cómo es el trabajo en equipo y la importancia de trabajar las habilidades comunicativas. Además, en muchos casos es muy probable que, en determinados momentos del proceso, tengan que interactuar con expertos de diferentes áreas de conocimiento, de comunidades e, incluso, de países y lenguas diferentes, lo que les muestra la necesidad de aprender idiomas, documentarse sobre otras culturas y adecuarse al contexto comunicativo, empleando para ello el registro y las herramientas lingüísticas necesarias.

\subsection{Las cinco etapas del DT}

Una vez hecha una pequeña argumentación sobre la necesidad de implementar un enfoque como el DT en las aulas de la era pos-COVID, vamos a explorar las cinco etapas fundamentales que integran el proceso del DT (véanse figura 1 y cuadro 2).

Figura 1. Las etapas del DT

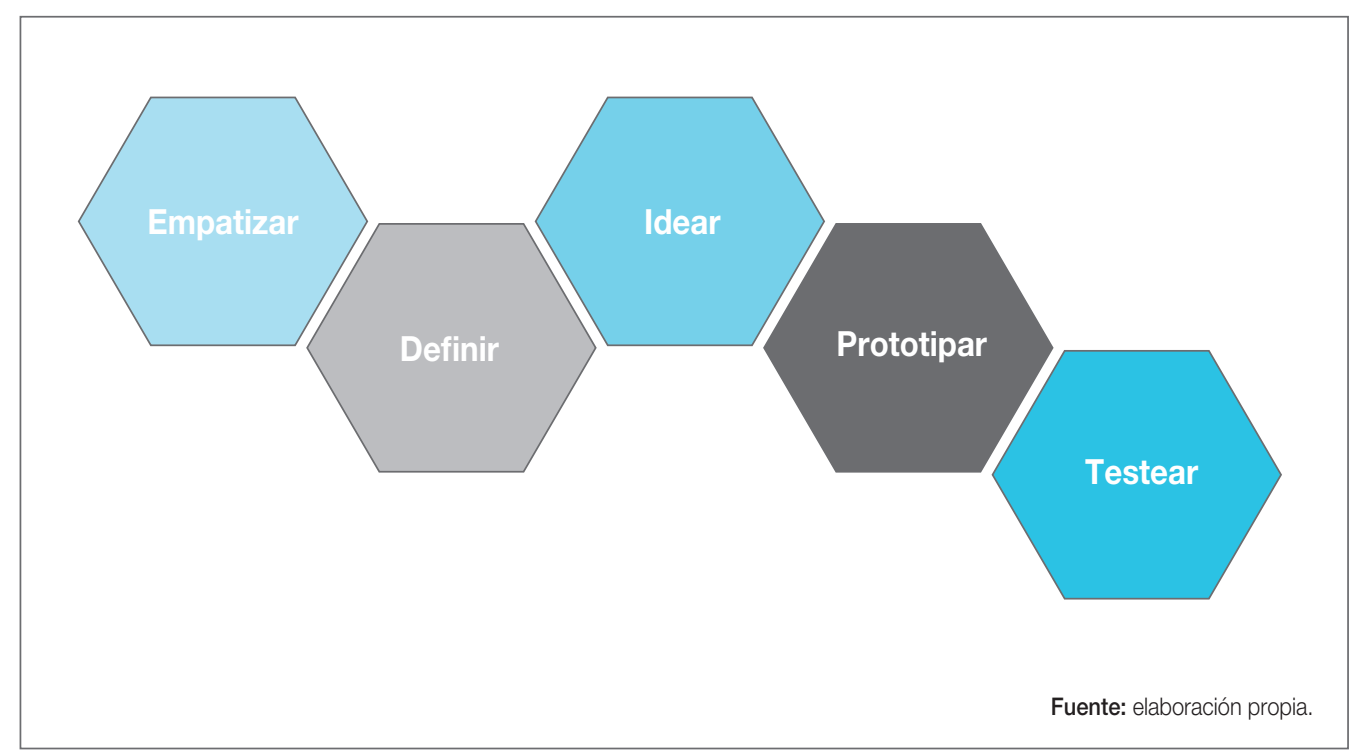




\section{Cuadro 2. Descripción de las cinco etapas del DT}

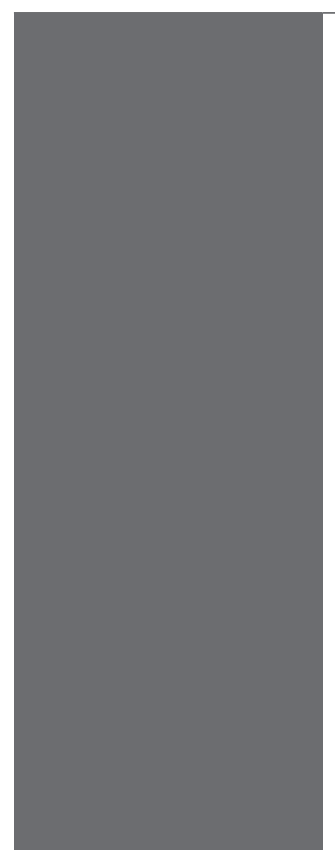

Etapa 1. Empatía
En esta primera fase, los estudiantes van a documentarse y a familiarizarse con los usuarios que, potencialmente, podrían beneficiarse del producto o servicio que hay que desarrollar, así como con el contexto que les rodea. En este sentido, Brown (2009) describe el trabajo de empatía como «un esfuerzo que ha de realizar el alumno para intentar ver a través de los ojos de los otros, intentar comprender el mundo a través de sus experiencias y sentir el mundo a través de sus emociones» (p. 53).

Algunas de las propuestas que define Lee (2018) en su libro a fin de que los estudiantes "ganen empatía» pasan, por ejemplo, por realizar entrevistas personales, llevar a cabo encuestas, recurrir a la técnica de observación directa, realizar experiencias de inmersión o llevar a cabo una pequeña investigación. Si bien este tipo de procedimientos pueden resultar en un primer momento un tanto complejos y complicados para los discentes, la práctica y el uso de diferentes estrategias facilitarán enormemente la tarea de investigación y recogida de datos.

Es aquí interesante destacar que, a fin de que la fase de empatía pueda desarrollarse debidamente, es fundamental que los estudiantes sean conscientes de su propia identidad, de sus emociones, de sus prejuicios, de sus preferencias $y$, en general, de todo aquello que pueda condicionarlos a la hora de intentar pensar o sentir como el usuario o el grupo de usuarios al que va a dirigirse su producto o servicio.

De acuerdo con Piaget, a partir de los seis años de edad los niños empiezan a ser menos egocéntricos y a desarrollar la habilidad para «ponerse en la piel del otro", lo que se traduce en una capacidad para responder y atender a las necesidades de sus iguales. Sin embargo, y puesto que a esa edad aún no han terminado de desarrollar por completo la empatía, la mayoría tiende a extrapolar sus gustos personales y particulares a las necesidades del otro. Sorprendentemente, esto no es solo una cualidad de los niños, pues también es algo que les sucede a los adultos (Lee, 2018), quienes tienen la tendencia a crear y diseñar en función de sus propias experiencias y necesidades. Es por esta razón por la que este paso suele ser, además del más complicado, el más importante del proceso, pues el éxito -o el fracaso- del producto o servicio final creado dependerá, en buena medida, de una buena identificación y definición del perfil del usuario final.

En un modelo de aprendizaje en remoto, el desarrollo de la competencia emocional puede resultar especialmente complicado, pues no se cuenta con un contexto que favorezca el contacto físico, la afectividad, la comunicación no verbal o los contextos comunicativos espontáneos. Es por ello que el DT, gracias a su punto de partida basado en el desarrollo de la empatía, puede suponer una excelente alternativa para trabajar la afectividad y el componente emocional. 


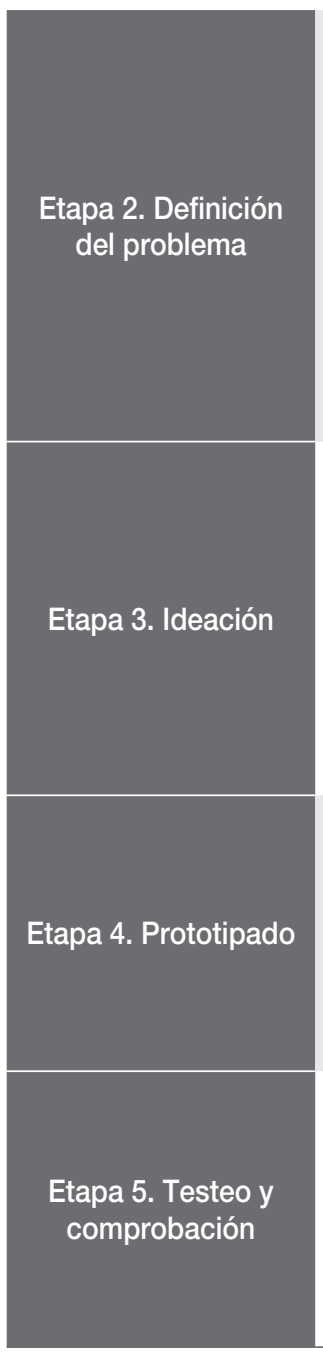

Esta etapa consiste en un proceso de síntesis de la información previamente recolectada por parte de los estudiantes con el fin de plantear una posible problemática, la cual definirá el reto que guiará todo el proceso del DT. Dicho planteamiento deberá identificar, de manera detallada, quién es el usuario que va a beneficiarse del producto o servicio, sus necesidades y cualquier otro aspecto de relevancia que se haya recogido durante la fase previa. Es importante señalar en este punto que, durante esta fase, los estudiantes no deben esforzarse por encontrar una solución al problema, sino exponer lo que el producto o servicio podría hacer por los usuarios o lo que los usuarios podrán conseguir gracias al uso de dicho producto o servicio.

En esta etapa los estudiantes intentan dar forma y conectar todos los datos recogidos en la fase de empatía con el fin de generar múltiples ideas que puedan dar solución a la problemática planteada. Esta fase supone una transición entre la etapa de identificación y documentación del problema y la parte más creativa, basada en la generación de ideas. El objetivo en este estadio es producir tantas ideas como sea posible -sin juzgar si son correctas o incorrectas- para, posteriormente, realizar un proceso de eliminación y seleccionar exclusivamente aquellas que resulten más factibles y viables.

Esta etapa consiste en transformar las ideas seleccionadas en la fase previa en prototipos visuales y tangibles que puedan dar solución a la problemática planteada. El prototipo, consistente en un modelo experimental, podrá ser presentado de manera esquemática y visual al resto de compañeros, quienes realizarán preguntas y proporcionarán feedback, creando así un contexto enriquecedor y estimulante que servirá para la posterior reflexión.

Esta etapa permite a los estudiantes obtener feedback y un conocimiento más exhaustivo del funcionamiento del producto o servicio prototipado. A través de las distintas pruebas es posible identificar aquellos aspectos del prototipo que no funcionan correctamente o que son susceptibles de mejora. Durante este proceso, los alumnos aprenden que los errores forman parte inexorable del proceso de aprendizaje y que es precisamente a través de ellos como mejor pueden aprender.

Fuente: elaboración propia.

\section{Los beneficios del DT en el aula de segundas lenguas}

El dominio de lenguas extranjeras se ha convertido en uno de los pilares fundamentales para lo que el Consejo de Europa llama «educación global, intercultural y plurilingüe», un modelo de educación que pretende responder a los retos que plantea un mundo diverso, sujeto a constantes cambios, y cada vez más interconectado, fundamentalmente a través de las tecnologías de la información y la comunicación (TIC). 
La creciente globalización ha convertido el aprendizaje de lenguas extranjeras en el principal instrumento de acceso a la información y al conocimiento, así como en herramienta indispensable para la participación en una variedad de contextos y de situaciones que suponen un estímulo para el desarrollo del individuo y que se traducen en mejores oportunidades en los ámbitos personal, académico, ocupacional, laboral o profesional.

Dentro de este contexto, el desarrollo de la competencia comunicativa en lengua extranjera se ha convertido en una de las prioridades de nuestro sistema educativo.

Sin embargo, alcanzar este objetivo no resulta tarea fácil, pues el aprendizaje de una segunda lengua supone, según se estipula en el Marco Europeo de Lenguas, el desarrollo de un conjunto de subcompetencias lingüísticas, sociolingüísticas y pragmáticas, el diseño de un currículo trasversal que tenga en cuenta contenidos y destrezas y la implementación de un enfoque educativo que facilite el desarrollo de todos estos elementos de manera combinada.

Para integrar todos estos aspectos es necesario que el proceso de enseñanza-aprendizaje se articule en torno a tareas y proyectos significativos enfocados a la acción, a través de los cuales los estudiantes puedan desarrollar las competencias clave y adquirir los conocimientos necesarios para mejorar sus destrezas de comprensión, producción e interacción oral y escrita.

Estas tareas y proyectos han de suponer situaciones comunicativas y de aprendizaje reales y ser extrapolables fuera del aula para, de esta manera, conseguir que el aprendizaje resulte verdaderamente significativo.

En este sentido, y en consonancia con todos los argumentos que se han ido desarrollando y justificando a lo largo del presente trabajo, el enfoque del DT se perfila como uno de los más indicados para conseguir los objetivos anteriormente mencionados.

Cuando ayudamos a nuestros estudiantes a desarrollar su pensamiento de diseño, les estamos proporcionando las herramientas necesarias para resolver problemas de su contexto cotidiano a través de procesos más empáticos, creativos e innovadores, al tiempo que les hacemos partícipes del urgente proceso de transformación y humanización de las diferentes esferas y sectores que conforman nuestra sociedad.
Dentro del contexto del aula de segundas lenguas, la mentalidad, los valores y el conjunto de habilidades que desarrolla el DT en los aprendientes, gracias a los procesos de pensamiento implícitos en las diferentes etapas, les hace más tolerantes y sensibles a los problemas culturales y a aquellos directamente relacionados con la lengua y la cultura, como los conflictos culturales, la discriminación racial y/o lingüística, los problemas de mediación e identidad, los estereotipos o la globalización, entre otros 
Dentro del contexto del aula de segundas lenguas, la mentalidad, los valores y el conjunto de habilidades que desarrolla el DT en los aprendientes, gracias a los procesos de pensamiento implícitos en las diferentes etapas, les hace más tolerantes y sensibles a los problemas culturales y a aquellos directamente relacionados con la lengua y la cultura, como los conflictos culturales, la discriminación racial y/o lingüística, los problemas de mediación e identidad, los estereotipos o la globalización, entre otros.

Por otro lado, el hecho de que el DT utilice la herramienta del visual thinking (VT)2 para hacer visibles los conceptos clave y los diferentes procesos mentales, o que el objetivo último suponga el diseño de un producto/servicio, facilita que tanto el proceso de aprendizaje como los procedimientos de evaluación se hagan más visibles y tangibles para el docente y los discentes.

Otro aspecto positivo derivado de la implementación del enfoque del DT en el aula es el desarrollo integrado de otras competencias clave recogidas en el currículo educativo, como la competencia de «aprender a aprender», las «sociales y cívicas», de «iniciativa y espíritu emprendedor», las de «conciencia y expresiones culturales» y la competencia «cultural».

\section{La competencia digital en el sistema educativo español: una mirada crítica}

La «competencia digital» descrita en la Orden ECD/65/2015 de 21 de enero se define como aquella capacidad que «implica el uso creativo, crítico y seguro de las TIC para alcanzar los objetivos relacionados con el trabajo, la empleabilidad, el aprendizaje, el uso del tiempo libre, la inclusión y participación en la sociedad».

Como se puede ver en la figura 2, la competencia digital se encuentra dividida en tres niveles:

- Saber (teoría).

- Saber hacer (práctica).

- Saber ser (actitudes y valores).

2 EI VT (pensamiento visual) es una herramienta que consiste en volcar y manipular ideas a través de dibujos simples y fácilmente reconocibles, creando conexiones entre sí por medio de mapas mentales, con el objetivo de entenderlas mejor, definir objetivos, identificar problemas, descubrir soluciones, simular procesos y generar nuevas ideas. 
Figura 2. Infografía sobre la competencia digital

\section{Competencia digital}
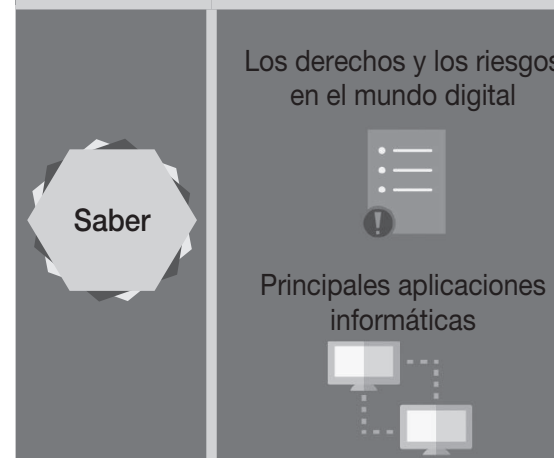

Lenguaje específico:

en el mundo digital

textual, numérico, icónico,

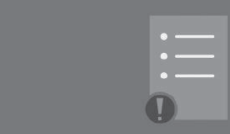
visual, gráfico y sonoro

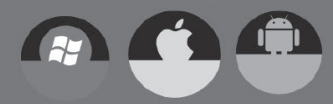

Principales aplicaciones

Fuentes de informáticas información

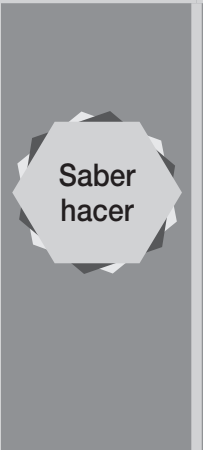

Utilizar recursos tecnológicos

Usar y procesar para la comunicación y resolución de problemas información de manera

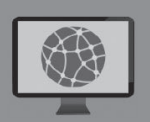

Buscar, obtener y tratar información

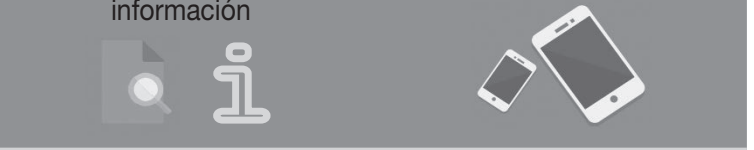
crítica y sistemática

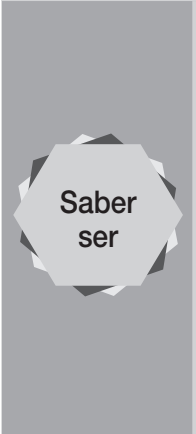

Tener una actitud activa, crítica y realista hacia las tecnologías y los medios tecnológicos
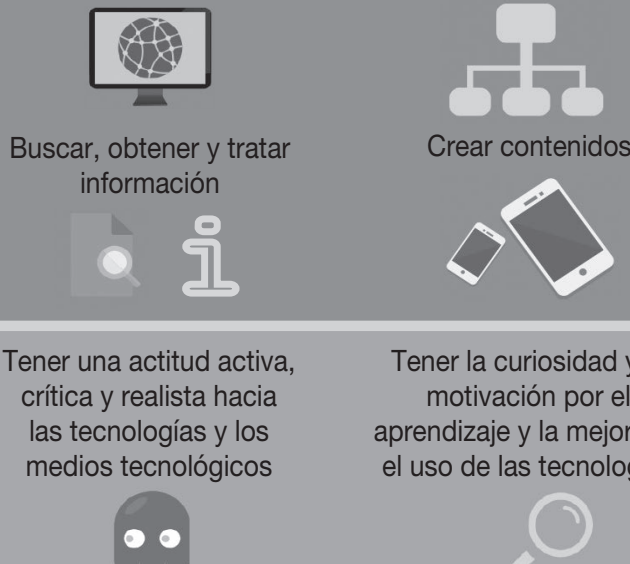

Valorar fortalezas y debilidades de los medios tecnológicos

Respetar principios éticos en su uso motivación por el aprendizaje y la mejora en el uso de las tecnologías

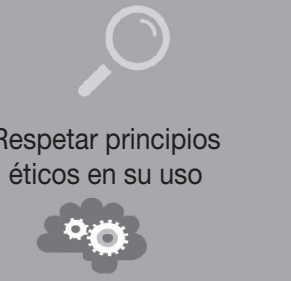

\section{LOM M}

Fuente: http://www.educacionyfp.gob.es/dam/jcr:aac96a77-cbf5-4f36-a65d-5fb131f9b921/competencia-digital-log.png 
El desarrollo de la competencia digital estipulada por la LOMCE supone el aprendizaje y la consolidación de conocimientos que tienen que ver con el lenguaje específico básico: textual, numérico, icónico, visual, gráfico y sonoro, así como sus pautas de decodificación y transferencia. Este aprendizaje, en última instancia, deberá traducirse en el conocimiento y en el correcto uso de las principales aplicaciones informáticas y herramientas digitales disponibles, así como en el conocimiento de los derechos y las libertades que asisten a los usuarios en el contexto digital.

De acuerdo con lo estipulado en el currículo educativo, la adquisición de esta competencia requiere, además, el desarrollo de actitudes y valores que permitan al usuario adaptarse a las nuevas necesidades establecidas por las tecnologías, una actitud activa, crítica y realista hacia las tecnologías y los medios tecnológicos, valorando sus fortalezas y debilidades y respetando los principios éticos en su uso. Por otra parte, la competencia digital implica la participación y el trabajo colaborativo, así como la motivación y curiosidad por el aprendizaje y la mejora en el uso de las tecnologías.

Sin embargo, con la aparición de la COVID-19 y la consiguiente «migración forzosa» del aula presencial a un modelo de enseñanza virtual, las carencias del sistema educativo español se han dejado notar. Según el Informe sobre el Progreso Digital en Europa 2017, de la Comisión Europea, en España solo el 53 \% de los ciudadanos tienen habilidades digitales básicas. En lo que respecta al ámbito educativo, el informe señala que solamente un $10 \%$ de los centros educativos españoles repartidos por la geografía del territorio español cuenta con dispositivos digitales en las aulas.

De acuerdo con el informe anteriormente mencionado, a pesar de que cada vez hay más españoles que tienen acceso a internet, «los niveles de competencias digitales básicas y avanzadas siguen siendo inferiores a la media de la Unión Europea. Únicamente el 53 \% de los ciudadanos de entre 16 y 74 años disponen de competencias digitales básicas, frente al $56 \%$ del resto de miembros de la Unión Europea, y los especialistas en TIC representan un porcentaje inferior de la población activa (2,4\%, en comparación con el 3,5\% en la Unión Europea)» (Docplayer, 2017, p. 5). Estos datos resultan especialmente sorprendentes cuando, según el Informe Eurydice de 2019, titulado Digital Education at School in Europe, sobre la importancia de la educación digital y la forma en la que se presenta en las políticas educativas europeas, España es uno de los países que incluye la competencia digital como una competencia clave y que la incorpora a su currículo educativo como materia indispensable, además de trabajarla de manera transversal.

El informe también pone de manifiesto que España ha desarrollado su propio marco de competencia digital para docentes, con una detallada descripción de cada una de las competencias: el Marco de Referencia de la Competencia Digital Docente. Se trata de un marco de referencia para el autodiagnóstico de las competencias digitales del profesorado, compuesto de 5 áreas competenciales y 21 competencias estructuradas en seis niveles de manejo, similares a los niveles de competencia en lengua extranjera -niveles A, B y C-. Cada 
una de estas competencias ofrece una descripción detallada, así como descriptores basados en términos de conocimientos, capacidades y actitudes, a modo de rúbrica de evaluación. Este marco es la base del Portfolio de la Competencia Digital Docente, instrumento digital publicado por el Instituto Nacional de Tecnologías Educativas y de Formación del Profesorado (INTEF) para la acreditación de dicha competencia (Toolkit del Portfolio de la Competencia Digital Docente).

De igual modo, en el informe se señala el papel de relevancia que juegan las autoridades educativas en el sistema educativo español, las cuales están implicadas en la provisión de un desarrollo profesional continuo para los docentes en materia de educación digital. Sin embargo, en el escrito también se indica que los docentes españoles no han sido nunca evaluados formalmente a través de una prueba objetiva de competencia digital a nivel nacional.

En cuanto a la evaluación de la competencia digital del alumnado, esta suele ser de carácter individual y está centrada, principalmente, en la realización de ejercicios y actividades que requieren de procesos cognitivos de orden inferior (Bloom, 1959) -recordar, comprender, aplicar-, dejando a un lado, en la mayoría de los casos, los procesos cognitivos de orden superior -analizar, evaluar y crear-, aquellos que tienen que ver con las tareas no rutinarias propuestas en el estudio de Autor (2003).

En vista de lo expuesto, parece una necesidad abogar por un enfoque educativo que facilite y permita la incorporación e integración de herramientas digitales colaborativas y de evaluación en los diferentes procesos y procedimientos, que permita la creación de un entorno virtual de aprendizaje retroalimentado por la mejora constante de la competencia digital de sus miembros y que sea capaz de transformar a sus usuarios en prosumidores críticos, capaces de producir y consumir contenido digital de manera responsable.
Parece una necesidad abogar por un enfoque educativo que facilite y permita la incorporación e integración de herramientas digitales colaborativas y de evaluación en los diferentes procesos y procedimientos, que permita la creación de un entorno virtual de aprendizaje retroalimentado por la mejora constante de la competencia digital de sus miembros y que sea capaz de transformar a sus usuarios en prosumidores críticos, capaces de producir y consumir contenido digital de manera responsable

\section{La enseñanza a distancia en el sistema educativo español}

El e-learning es una modalidad de enseñanza y aprendizaje en la que la interacción docente-discente y discente-discente tiene lugar en un aula virtual. En palabras de expertos en este campo, como Area y Adell (2009), el e-learning «consiste en el diseño, puesta en práctica y evaluación de un curso o plan formativo desarrollado a través de redes de ordenadores y 
puede definirse como una educación o formación ofrecida a individuos que están geográficamente dispersos o separados o que interactúan en tiempos diferidos del docente empleando los recursos informáticos y de telecomunicaciones» (p. 2).

En España, la enseñanza a distancia o e-learning es ya una realidad consolidada en la mayoría de los sectores sociales, corporativos y formativos. Las Administraciones públicas, así como las empresas privadas están volcando el grueso de sus recursos en desarrollar la mayor parte de su oferta formativa a través de esta modalidad educativa apoyada en internet (Area y Adell, 2009).

Esta modalidad de enseñanza se encuentra en pleno crecimiento y actualización como consecuencia de las necesidades formativas actuales, a saber: la dificultad para poder asistir de manera regular y presencial a centros de enseñanza físicos, la expansión de la educación universitaria y la importancia de la actualización formativa (Rubio, 2014).

Una de las principales ventajas que ofrece el modelo de enseñanza a distancia es que permite flexibilizar horarios y superar las restricciones de tiempo de los usuarios, así como la adecuación al propio ritmo de aprendizaje de cada aprendiente. Asimismo, la implementación de la modalidad a distancia puede tener repercusiones de carácter social, pues abre una vía a la democratización de la enseñanza y acerca la educación a los avances tecnológicos (Rubio, 2014). Dentro del contexto académico, algunas de las ventajas de la modalidad e-learning que destacan en su estudio Area y Adell (2009) son las que se muestran en el cuadro 3:

\section{Cuadro 3. Los beneficios del e-learning}

\section{¿Qué aporta el e-learning a la mejora e innovación de la enseñanza?}

Extender y facilitar el acceso a la formación a colectivos e individuos que no pueden acceder a la modalidad presencial.

Incrementar la autonomía y responsabilidad del estudiante en su propio proceso de aprendizaje.

Superar las limitaciones provocadas por la separación en espacio y/o tiempo del profesor-alumnos.

Gran potencial interactivo entre profesor-alumno.

Flexibilidad en los tiempos y espacios educativos.

Acceder a multiplicidad de fuentes y datos diferentes de los ofrecidos por el profesor en cualquier momento y desde cualquier lugar.

Aprendizaje colaborativo entre comunidades virtuales de docentes y estudiantes. 
Hace tan solo unos años, el esfuerzo de empresas y Administraciones se centraba, fundamentalmente, en mejorar los aspectos más puramente tecnológicos de la modalidad del e-learning. Cuestiones como las infraestructuras de las telecomunicaciones o de determinadas plataformas informáticas supusieron, en aquel momento, la principal preocupación de los agentes implicados en la creación de sistemas de formación a través de internet, como señalan Area y Adell (2009) en su trabajo. Posteriormente, el interés de estos agentes se centró en generar plataformas compatibles que facilitaran el intercambio y la reusabilidad de contenidos entre cursos. Actualmente, el foco de atención está puesto, sobre todo, en aspectos más puramente pedagógicos, como la calidad del diseño del material ofrecido, los procedimientos e instrumentos de evaluación o la calidad de la tutorización.

En lo concerniente a los niveles educativos reglados, desde la educación primaria a la educación superior, las plataformas de enseñanza a distancia desempeñan funciones diversas: «Repositorios de materiales, gestión y evaluación de los trabajos de los estudiantes, recursos de información y noticias, comunicación y tutorización, etc.» (Area y Adell, 2009, p. 25). En muchos casos, los centros educativos o las propias editoriales ofrecen este tipo de plataformas a los docentes, a los alumnos y a las familias como espacios o aulas virtuales dedicados a compartir material didáctico extra o a motivar al alumnado empleando para ello elementos de la gamificación. Si bien es cierto que muchas organizaciones y entidades se han volcado en el diseño y en la creación de plataformas de este tipo, su nivel de complejidad en el uso o la ausencia de herramientas más intuitivas que faciliten la interacción en tiempo real entre los diferentes usuarios han hecho que queden relegadas exclusivamente a aulas virtuales de consulta con material de apoyo.

Por otro lado, el incremento de dispositivos móviles con conexión a internet y la proliferación de redes sociales y de herramientas digitales de libre acceso para la curación de contenidos han dado lugar a la aparición de las experiencias mobile learning, administradas y gestionadas directamente por docentes y alumnos, y de los entornos personales de aprendizaje (personal learning environment [PLE]), diseñados para favorecer el aprendizaje informal y el desarrollo profesional.

En la era pos-COVID, todo indica que una versión transformada y mejorada de la modalidad del e-learning, así como las experiencias mobile learning y los PLE se convertirán en grandes aliados en el proceso de enseñanza-aprendizaje en todos los niveles educativos, por lo que será necesario que tanto agentes políticos como educativos y económicos sumen esfuerzos para conseguir una implementación integral, sólida y efectiva de estos recursos.
En la era pos-COVID, todo indica que una versión transformada y mejorada de la modalidad del e-learning, así como las experiencias mobile learning y los PLE se convertirán en grandes aliados en el proceso de enseñanza-aprendizaje en todos los niveles educativos, por lo que será necesario que tanto agentes políticos como educativos y económicos sumen esfuerzos para conseguir una implementación integral, sólida y efectiva de estos recursos 
La curación y estructuración de los contenidos se torna una de las principales preocupaciones en relación a la calidad de la enseñanza online (Rubio, 2013), pues el hecho de trabajar a distancia implica la consecuente adecuación de los materiales, de tal manera que se garantice el aprendizaje. Del mismo modo, algunas de las preocupaciones que manifiestan los docentes en relación al modelo de enseñanza en remoto son la periodicidad de las tutorías, las videoconferencias en directo, los procedimientos de evaluación, la afectividad (el componente emocional) o la brecha digital.

En lo referente a la tutorización de los procesos de enseñanza a distancia, los procesos de evaluación o las sesiones en línea, cabe aquí señalar que todos estos aspectos van a verse afectados notablemente por la consolidación de las tecnologías de la comunicación y la creciente oferta de herramientas digitales. Además, el hecho de que las tecnologías de la información están alterando el modo de acceder al conocimiento, el papel, tanto del profesorado como del alumnado, va a sufrir también importantes transformaciones. En el caso del docente, este adoptará un papel más secundario, de guía-acompañante, mientras que el alumno pasará a un primer plano, tomando las riendas de su propio aprendizaje, lo cual se traducirá en un cambio radical en las herramientas digitales, en las metodologías, en los modelos y en los enfoques educativos hasta ahora empleados.

\section{Diseño de un proyecto de innovación educativa a distancia para el aula de idiomas a través del DT}

Docentes a la vanguardia en enseñanza a distancia y en DT, como Spencer y Juliani (2016), hablan de una profunda transformación en la predisposición al aprendizaje por parte de sus alumnos, de un notable incremento de la empatía y de un salto cualitativo en la creatividad de sus alumnos tras la implementación del DT en sus aulas en línea.

Asimismo, numerosos expertos en educación que han trabajado con el DT y lo han incorporado a su práctica docente han reconocido la existencia de una conexión natural entre este enfoque y la manera en la que se articulan los contenidos, los objetivos, los estándares y las competencias curriculares.

\subsection{Objetivos específicos del proyecto de innovación}

La presente propuesta de innovación persigue que todos los aprendientes:

- Colaboren e interactúen en grupo y por parejas de manera síncrona y asíncrona.

- Tomen las riendas de su propio aprendizaje y se conviertan en aprendientes autónomos. 
- Desarrollen la capacidad de indagación y síntesis, así como el pensamiento crítico y creativo a lo largo de las diferentes etapas y tareas propuestas.

- Practiquen la segunda lengua en contextos reales a través de tareas significativas.

- Creen materiales digitales e interactivos de manera individual y colaborativa.

- Desarrollen su empatía.

- Trabajen y mejoren su competencia digital en contexto a partir del descubrimiento y uso de diversas herramientas de curación de contenidos.

\subsection{Objetivos específicos de área y comunes a todas las pro- puestas}

Estos objetivos serían los que enumeramos a continuación:

- Comprender información general y específica de textos orales en la segunda lengua en situaciones comunicativas variadas.

- Expresarse e interactuar oralmente en la segunda lengua en situaciones habituales de comunicación, dentro y fuera del aula, de forma eficaz, adecuada y con cierto nivel de autonomía.

- Leer y comprender de forma autónoma diferentes tipos de textos escritos en la segunda lengua con el fin de extraer información general y específica y de utilizar la lectura como fuente de placer, de enriquecimiento personal y de conocimiento de otras culturas.

- Escribir de forma eficaz en la segunda lengua textos sencillos con finalidades diversas, sobre distintos temas, mediante recursos adecuados de cohesión y coherencia.

- Utilizar de forma reflexiva y correcta los elementos básicos de la lengua -fonética, léxico, estructuras y funciones- en contextos diversos de comunicación.

- Desarrollar la autonomía en el aprendizaje, reflexionar sobre los propios procesos de aprendizaje y transferir al conocimiento de la lengua extranjera los conocimientos y las estrategias de comunicación adquiridas en la lengua materna o en el aprendizaje de otras lenguas.

- Utilizar las estrategias de aprendizaje y los recursos didácticos a su alcance (diccionarios, libros de consulta, materiales multimedia), incluidas las TIC, para la obtención, selección y presentación de la información oral y escrita de forma autónoma.

- Reflexionar sobre el funcionamiento de la lengua extranjera y apreciarla como instrumento de acceso a la información y como herramienta de aprendizaje de contenidos diversos. 
- Valorar la lengua extranjera y las lenguas en general como medio de comunicación y entendimiento entre personas de procedencias, lenguas y culturas diversas, evitando estereotipos lingüísticos y culturales o cualquier forma de discriminación.

- Manifestar una actitud receptiva y de autoconfianza en las capacidades de aprendizaje y en el uso de la lengua extranjera.

\subsection{Descripción del grupo meta}

El grupo beneficiario de la propuesta de innovación está conformado por 10 estudiantes adolescentes de cuarto de educación secundaria obligatoria (ESO) que acuden a clases extraescolares de inglés a The Language House, un centro de idiomas de carácter privado ubicado en la localidad castellano-manchega de Campo de Criptana. El grupo de estudiantes asiste al mismo centro de enseñanza reglada y presenta un nivel de segunda lengua bastante homogéneo en las cuatro destrezas principales del idioma. Asimismo, todos los integrantes están preparando su examen de Cambridge nivel B2 (FCE). Las propuestas de actividades se diseñaron en función de los dispositivos electrónicos con los que contaban los estudiantes.

\subsection{Metodología}

El proyecto de innovación está integrado por tres actividades principales articuladas en torno al enfoque del DT y desarrolladas por etapas. Durante las nueve semanas de trabajo, los estudiantes trabajaron en remoto, de manera síncrona y asíncrona, en grupos, por parejas e individualmente, interactuando en la segunda lengua (inglés). A fin de facilitar la interacción y el trabajo en remoto, los alumnos hicieron uso de las siguientes herramientas digitales con diferentes propósitos (véase cuadro 4):

Cuadro 4. Herramientas digitales para el aprendizaje en remoto

\begin{tabular}{ll}
\hline Plataforma para videoconferencias. & Zoom \\
$\begin{array}{ll}\text { Toma de notas, brainstorming colaborativo, foros } \\
\text { de debate, cuadernos interactivos y encuestas. }\end{array}$ & $\begin{array}{l}\text { Google Classrooms } \\
\text { Google Docs } \\
\text { Google Forms } \\
\text { Flipgrid }\end{array}$ \\
\hline $\begin{array}{l}\text { Lecturas (recopilación de artículos online en prensa } \\
\text { internacional). }\end{array}$ & Padlet \\
\hline
\end{tabular}


Siguiendo los principios postulados por el DT y el MM, los alumnos tomaron las riendas de su propio proceso de aprendizaje, asumiendo así un papel más protagonista y de empoderamiento. Tanto las actividades como las herramientas que se iban a emplear se explicaron de manera general a todos los alumnos al comienzo de cada etapa para que, posteriormente, pudieran realizar un trabajo más autónomo. Asimismo, se ofrecieron tutorías en línea para aclarar dudas y dar apoyo a aquellos estudiantes que así lo solicitaron.

\section{A través de las diferentes etapas del proceso del D'T, los discentes fueron desarrollando su pensamiento creativo y empatía, al tiempo que aprendían a colaborar, gestionar y sintetizar la información y practicaban su segunda lengua en entornos más naturales y significativos}

A través de las diferentes etapas del proceso del DT, los discentes fueron desarrollando su pensamiento creativo y empatía, al tiempo que aprendían a colaborar, gestionar y sintetizar la información y practicaban su segunda lengua en entornos más naturales y significativos.

En línea con lo que señalan Area y Adell (2009), el material didáctico y las actividades desarrolladas se diseñaron para propiciar un proceso de aprendizaje activo por parte del alumnado y generar situaciones comunicativas variadas que favoreciesen la interacción, así como el intercambio de conocimientos y experiencias.

Figura 3. E-learning: enseñar y aprender en espacios virtuales

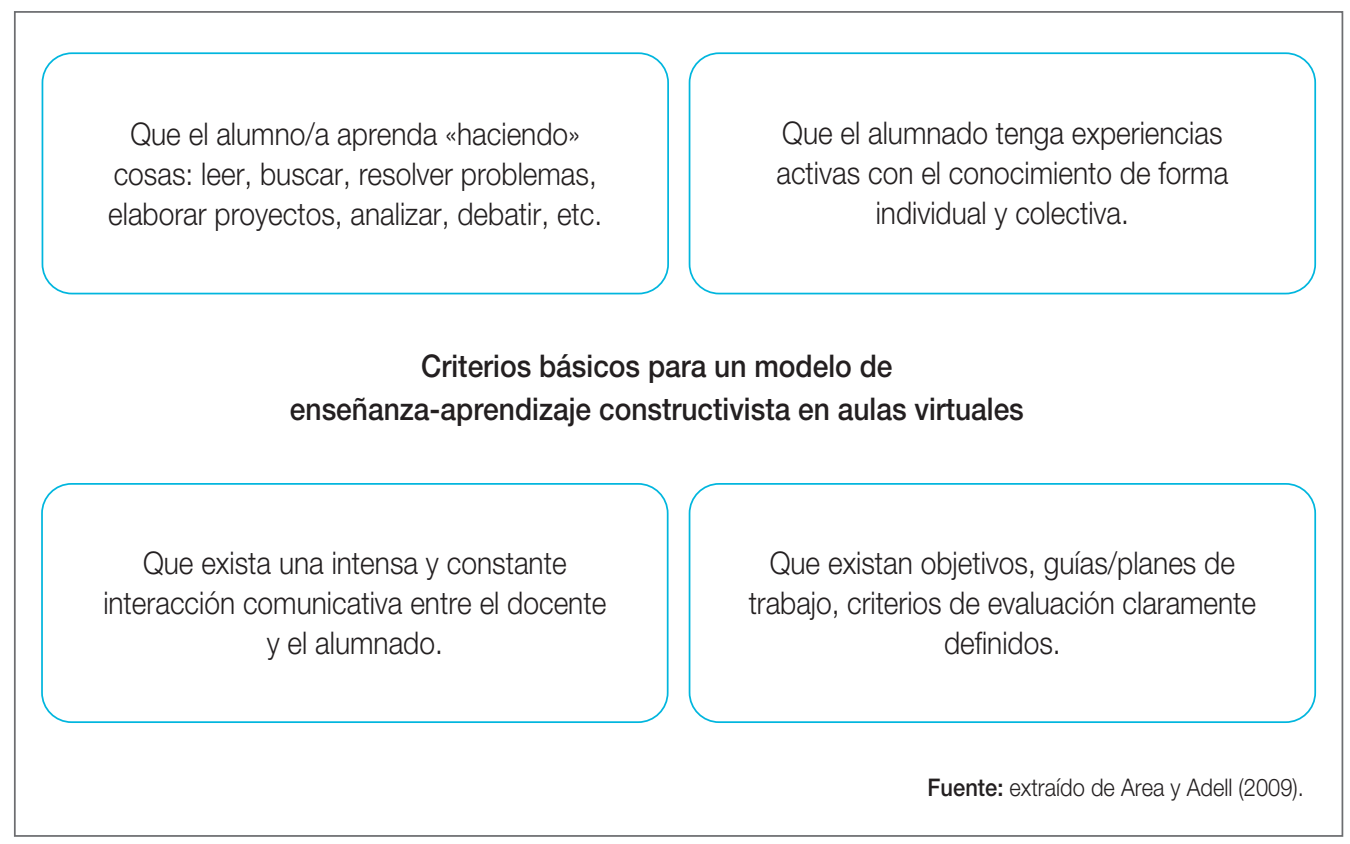


Durante toda le experiencia, los alumnos trabajaron con documentos compartidos de Google a fin de facilitar al docente la supervisión continuada del trabajo, quien revisó dichos documentos de manera semanal para poder proporcionar el feedback necesario y realizar las correcciones pertinentes.

\section{ACTIVIDAD 1}

- Centro: The Language House.

- Localización: Campo de Criptana (Castilla-La Mancha).

- Modelo de enseñanza: modalidad en línea (síncrona y asíncrona).

- Temporalización: 3 semanas.

- Edad y curso académico: $4 .^{\circ}$ de ESO.

- Nivel de lengua (L2) inglés: B2/FCE.

- Número de alumnos: 10 (divididos por parejas).

- Herramientas digitales: Zoom, Genially, Google Forms y Padlet.

A) Objetivo espećifico de la actividad

Diseñar y presentar una propuesta o plan de actuación para ayudar a hoteles, bares y restaurantes de la zona a adaptarse a las exigencias de la era pos-COVID.

B) Pregunta de partida

¿Qué pueden hacer el sector del turismo y de la restauración para reinventarse y sobrevivir en la época pos-COVID?

C) Impacto

Los estudiantes proporcionaron ideas concretas a los negocios del sector servicios de su comunidad con la finalidad de ayudarles a atraer clientes y a que se adaptaran a las particularidades y a las exigencias de la era pos-COVID, en un intento por promover la economía local.

D) Proceso

- Empatía. En la primera videoconferencia se propuso a los estudiantes la lectura y el análisis de dos proyectos concretos: la iniciativa Separate Greenhouses, promovida por Mediamatic ETEN, un restaurante vegano ubicado en el centro de las artes Mediamatic Biotoop, en Ámsterdam; y Plex'Eat, una propuesta de lámparas decorativas aislantes diseñadas por Christophe Gernigon. Tras la lectura de ambas propuestas, se invitó a los estudiantes a dejar sus impresiones y comentarios en un documento compartido supervisado por el docente.

Seguidamente, se animó al alumnado a diseñar y distribuir formularios de Google en su comunidad más inmediata para averiguar cuáles eran sus principales miedos y reparos en lo referente al uso de instalaciones como bares, restaurantes u hoteles. 
- Definición del problema. Una vez analizadas las propuestas y los datos desprendidos de los formularios, cada pareja pasó a seleccionar y definir una de las problemáticas identificadas.

- Ideación. A partir de la problemática identificada, las parejas de estudiantes realizaron una lluvia de ideas en un documento compartido para proponer diferentes soluciones.

- Prototipado. En esta fase, los alumnos se sirvieron de bocetos realizados manualmente o con sus tabletas para mostrar de manera visual la posible solución a la problemática que habían planteado. En otros casos, también se realizaron presentaciones interactivas con imágenes para mostrar las soluciones identificadas, así como su viabilidad.

- Testeo y comprobación. En la última fase, los alumnos pusieron en común sus bocetos y anotaciones en una videoconferencia grupal, aportando sus opiniones personales sobre el trabajo de los compañeros para ayudarles a perfilar sus prototipos y creaciones. Finalmente, el profesor animó al alumnado a enviar algunas de sus propuestas -en español- a las autoridades competentes a fin de aportar ideas y soluciones alternativas al gremio de comerciantes y restauradores de su localidad.

\section{ACTIVIDAD 2}

- Centro: The Language House.

- Localización: Campo de Criptana (Castilla-La Mancha).

- Modelo de enseñanza: modalidad en línea (síncrona y asíncrona).

- Temporalización: 3 semanas.

- Edad y curso académico: $4 .^{\circ}$ de ESO.

- Nivel de lengua (L2) inglés: B2/FCE.

- Número de alumnos: 10.

- Herramientas digitales: Zoom, Piktochart, Genially, Padlet, Google Docs, Forms y Flipgrid.

\section{A) Objetivo específico de la actividad}

Diseñar y crear material digital de consulta para las redes sociales y el blog oficial de clase.

B) Pregunta de partida

¿Cómo ayudar a los estudiantes a hacer su tiempo de estudio más eficiente, mejorar el rendimiento académico e incrementar sus niveles de bienestar durante el confinamiento?

C) Impacto

El proceso culminó con el diseño y la creación de material digital visual -infografías, imágenes interactivas y presentaciones- para compartir en las redes sociales y en el blog de clase con el fin de ayudar a compañeros y estudiantes de otros centros educativos a organizar mejor su tiempo de estudio en casa, a mejorar el rendimiento académico y, consecuentemente, a incrementar su grado/nivel de bienestar durante el confinamiento. 
D) Proceso

- Empatía. Durante una primera videoconferencia por Zoom con el grupo de estudiantes se propuso la lectura de varios artículos extraídos de la presa internacional. En la selección de artículos había testimonios de jóvenes de todo el mundo, quienes expresaban sus inquietudes y principales dificultades para organizar su tiempo de estudio, rendir académicamente durante el confinamiento y mantener una actitud positiva. Asimismo, los estudiantes diseñaron formularios y llevaron a cabo encuestas para tomar el pulso a su comunidad educativa más inmediata a fin de averiguar cuáles eran las principales preocupaciones y problemáticas con las que se encontraban los jóvenes a la hora de organizar su tiempo de estudio y trabajo en casa.

- Definición del problema. Tras la lectura de los artículos y la toma de datos a través de las entrevistas y formularios de Google, se pidió a los estudiantes que, individualmente, hicieran una labor de síntesis de la información previamente recolectada y dejaran sus impresiones por escrito en un documento de Google general compartido y supervisado por el docente.

Seguidamente, por parejas, los estudiantes tuvieron que identificar una problemática concreta y anotar 10 propuestas o consejos para dar solución a la problemática identificada.

- Ideación. En esta tercera fase, las parejas seleccionaron las soluciones que, en su opinión, eran más viables e investigaron por internet cómo podrían implementarse de manera satisfactoria, tomando en cuenta las circunstancias y características tan particulares del contexto del confinamiento.

- Prototipado. A continuación, y una vez realiza la fase de ideación, los estudiantes seleccionaron una herramienta de diseño -Piktochart, Genially, Canva, Word o PowerPoint- y elaboraron una infografía en la que aparecía un resumen de sus propuestas. Cuando los alumnos finalizaron el primer borrador, lo compartieron con el docente para que este pudiera supervisar la producción escrita y orientarles para subsanar posibles problemas de redacción, expresión o estética.

- Testeo y comprobación. En la última fase, los estudiantes volvieron a reunirse por videollamada para compartir sus diseños. Por turnos, cada pareja presentó su propuesta al resto, justificando la selección de la problemática, los consejos, así como la herramienta utilizada para realizar el diseño de la infografía. Para guiar la conversación y ayudar a los estudiantes a estructurar sus intervenciones, se proporcionó un breve listado de expresiones y preguntas tipo. Cuando todas las parejas recibieron el feedback de los demás compañeros, procedieron a acometer los cambios necesarios para mejorar sus creaciones. Finalmente, los estudiantes publicaron sus diseños en las redes sociales, en Flipgrid, así como en el blog oficial de clase para dar visibilidad y difusión a sus creaciones.

\section{ACTIVIDAD 3}

- Centro: The Language House.

- Localización: Campo de Criptana (Castilla-La Mancha).

- Modelo de enseñanza: modalidad en línea (síncrona y asíncrona).

- Temporalización: 3 semanas. 
- Edad y curso académico: $4 .^{\circ}$ de ESO.

- Nivel de lengua (L2) inglés: B2/FCE.

- Número de alumnos: 10.

- Herramientas digitales: Zoom, Genially, Piktochart, Padlet, Google Docs, Google Forms y Flipgrid.

A) Objetivo específico de la actividad

Diseñar una presentación en la que se exponga uno de los principales cambios que sufrirán las aulas en la era pos-COVID, así como consejos, estrategias y herramientas concretas para facilitar a la comunidad educativa (alumnos, profesorado y familias) el cambio y la transición al nuevo modelo de aula.

B) Pregunta de partida

¿A qué retos se enfrentan y cómo deben adaptarse las aulas de los centros educativos españoles en la era pos-COVID?

C) Impacto

Los estudiantes llevaron a cabo entrevistas y encuestas a través de las redes sociales, la plataforma Flipgrid y los formularios de Google para averiguar el sentir de la comunidad educativa sobre los posibles retos que afrontarían los centros educativos en España durante el curso escolar 2020/2021. Asimismo, elaboraron presentaciones grupales en las que expusieron posibles herramientas, estrategias y soluciones para facilitar la adaptación de la comunidad educativa al inminente cambio.

D) Proceso

- Empatía. Durante la primera videoconferencia, los estudiantes leyeron varios artículos de la prensa internacional para ver cómo estaban adaptándose centros y sistemas educativos de todo el mundo a la vuelta progresiva a las aulas. Las noticias fueron previamente seleccionadas meticulosamente para mostrar a los alumnos cómo centros de todo el mundo se preparaban para solventar posibles problemas de espacio físico y abordar los cambios a nivel social, afectivo, emocional y de aprendizaje. Tras una lectura preliminar, los participantes anotaron las ideas centrales en un documento compartido de Google y debatieron sobre cuáles podrían implementarse en los centros españoles, dada su particular idiosincrasia. Seguidamente, los estudiantes elaboraron cuestionarios interactivos en Google Forms para averiguar las impresiones y opiniones de su comunidad educativa más inmediata. Asimismo, invitaron a otros miembros de la comunidad a participar enviando un minivídeo a través de la plataforma Flipgrid.

- Definición del problema. Tras las lecturas, los debates y las encuestas, los estudiantes reflexionaron sobre los diferentes escenarios que se abren de cara al próximo curso: enseñanza en remoto, modelo híbrido, enseñanza presencial por turnos, clases por streaming, etc., así como las consecuencias que estas podrían tener en los ámbitos social, afectivo-emocional, psicológico, económico, ergonómico y, sobre todo, en el propio proceso de enseñanza-aprendizaje. Seguidamente, los estudiantes seleccionaron uno de estos ámbitos y llevaron a cabo una lluvia de ideas sobre las posibles herramientas y estrategias susceptibles de ser aplicadas para ayudar a la comunidad educativa a adaptarse, sin prestar aún atención a la viabilidad de las mismas. 
- Ideación. En esta tercera fase, las parejas seleccionaron cinco de las propuestas que, en su opinión, se perfilaban como las más viables y emprendieron un proceso de investigación sobre cómo implementarlas de manera satisfactoria, tomando como referencia artículos de la prensa internacional y otros recursos ofrecidos por el docente.

- Prototipado. A continuación, por parejas, elaboraron una presentación en la que detallaron, por un lado, las posibles repercusiones para el ámbito seleccionado, así como sus propuestas y sugerencias para ayudar a la transición y a la adaptación a la nueva situación tanto al profesorado como al alumnado y a las familias.

- Testeo y comprobación. Para la última fase, los estudiantes se reunieron por videollamada para compartir sus conclusiones. Por turnos, cada pareja presentó sus retos y propuestas. Cuando todas las parejas recibieron el feedback de los demás compañeros, procedieron a realizar las mejoras necesarias en sus diseños para, posteriormente, publicar el material en las redes sociales y en el blog de clase, y generar el debate entre la comunidad educativa

\subsection{Evaluación del diseño de innovación}

A fin de comprobar de primera mano la efectividad del proyecto de innovación educativa presentado, así como la evolución y el progreso de los discentes, se diseñó un plan de evaluación exhaustivo y personalizado, integrado por diferentes herramientas e instrumentos de autoevaluación.

Por un lado, se emplearon test objetivos de progreso y rúbricas personalizadas para evaluar la competencia comunicativa, las cuales fueron creadas por el docente en documentos y formularios de Google para determinar el nivel de progreso en diferentes áreas:

- Producción escrita.

- Producción e interacción oral.

- Habilidades comunicativas.

- Competencia léxica y gramatical.

- Originalidad del diseño del material creado.

Asimismo, durante las videoconferencias y tutorías en línea, los estudiantes recibieron retroalimentación en relación a sus aportaciones realizadas en remoto y a la evolución de sus habilidades lingüísticas. A fin de invitar a los estudiantes a reflexionar sobre su papel dentro del grupo, así como su espíritu de colaboración, se les pidió, al término de las tres semanas de trabajo, que completasen una diana de autoevaluación interactiva donde señalasen su grado de implicación con las tareas a lo largo del proceso, sus aportaciones, la participación 
activa y su actitud para con los demás miembros de la clase en diferentes etapas. Para complementar la autoevaluación, los estudiantes tuvieron que redactar un diario de aprendizaje en un documento compartido con el profesor, detallando las dificultades surgidas en los diferentes procesos, las destrezas practicadas, la gramática y el léxico aprendido, las herramientas digitales empleadas y sus impresiones sobre el impacto de sus propuestas.

Finalmente, y a fin de registrar y dejar constancia del léxico nuevo aprendido tras cada una de las experiencias, los estudiantes diseñaron nubes interactivas de palabras empleando el vocabulario y las nuevas expresiones aprendidas a lo largo de la experiencia.

\section{Conclusiones}

En este apartado se va a procurar hacer un ejercicio de análisis y reflexión a fin de comprobar la efectividad del proyecto de innovación educativa implementado en un entorno de enseñanza-aprendizaje virtual y desarrollado durante un periodo de nueve semanas, para lo que se va a indicar el grado de consecución de los objetivos específicos del proyecto de innovación, así como los específicos de área.

Durante toda la experiencia, los estudiantes han colaborado en remoto, síncrona y asíncronamente, a fin de llevar a cabo las diferentes tareas propuestas en las actividades que conforman el proyecto y que les exigían colaborar en grupo, trabajar por parejas y de manera individual. Por su parte, el papel del docente ha sido, fundamentalmente, de acompañante y guía, invitando a los aprendientes a reflexionar, a analizar la información y a gestionar los recursos de manera autónoma e independiente en todas y cada una de las etapas del proceso.

Gracias a la tipología de las tareas y a los instrumentos de autoevaluación propuestos, los estudiantes han desarrollado su autonomía a partir del uso de estrategias de aprendizaje y de recursos didácticos a su alcance, reflexionando, al mismo tiempo, sobre los propios procesos de aprendizaje y sobre la lengua extranjera como instrumento de acceso a la información y herramienta de aprendizaje de contenidos diversos.

En cuanto a los objetivos específicos de área, no cabe duda de que las diferentes actividades propuestas han facilitado a los discentes trabajar con diferentes tipologías textuales en la segunda lengua, expresarse e interactuar oralmente en diversas situaciones comunicativas y redactar textos en la segunda lengua sobre temáticas variadas, empleando para ello los recursos lingüísticos necesarios.

En relación a la implementación del proyecto de innovación, algunas de las limitaciones que ha presentado han sido el escaso conocimiento por parte del alumnado de algunas de las herramientas digitales presentadas, lo cual se ha ido solventando con la práctica. Si 
bien es cierto que al comienzo los estudiantes se sintieron un poco sobrepasados por las características de las actividades y las tareas propuestas, al término de la experiencia la mayoría reportó por diferentes medios una enorme satisfacción personal, un incremento de su creatividad y una notable mejoría en su competencia comunicativa en lengua extranjera, además del evidente progreso en su competencia digital.

En conclusión, podría decirse que el enfoque del DT es capaz de promover un uso óptimo y eficiente de las herramientas de comunicación que tenemos a nuestro alcance gracias al avance de las TIC, así como la oportunidad de crear un entorno de enseñanza-aprendizaje constructivista y colaborador en el que los aprendientes son los protagonistas principales. En la sociedad de la información no podemos limitarnos a reproducir formas de aprendizajes, sino que debemos crear nuevos modos de aprendizaje a partir de las posibilidades creadas por las tecnologías emergentes (Attwell, 2007). Y este es precisamente el reto que todos los agentes de las comunidades educativas debemos afrontar en un momento de metamorfosis en todos los ámbitos de nuestra sociedad.

\section{Implicaciones futuras para la comunidad educativa}

El presente artículo se considera de gran utilidad, pues abre una línea de investigación poco explorada y que podría tener efectos muy positivos en la práctica docente y en el proceso de enseñanza-aprendizaje de segundas lenguas en entornos educativos virtuales. Una de las posibles líneas de investigación futuras que arrojaría datos objetivos sobre el estado de la cuestión pasaría por el diseño de una propuesta de intervención en una muestra mayor de población a partir de la cual se puedan analizar y extraer datos más objetivos sobre el comportamiento de la empatía, el nivel de competencia digital y el nivel de lengua de los discentes.

Si bien se ha observado y reportado una mejoría en la capacidad de empatía de los aprendientes a través de la observación directa y las entrevistas personales, se sugiere que, de cara a futuras investigaciones, se empleen instrumentos tipificados para medir el nivel de empatía al comienzo y al término de la propuesta de intervención, así como técnicas de neuroimagen que ayuden a estudiar el comportamiento del cerebro y su posible recableado a lo largo del proceso. Asimismo, también se sugiere la elaboración y el empleo de cuestionarios autoadministrables para medir de una manera más objetiva el grado de competencia digital del alumnado al comienzo y al término del procedimiento. 


\section{Referencias bibliográficas}

Area, M. y Adell, J. (2009). E-learning: enseñar y aprender en espacios virtuales, 1-30. https://www.researchgate.net/publication/ 216393113_ELearning_ensenar_y_aprender _en_espacios_virtuales

Arnheim, R. (1969). Visual Thinking. University of California Press.

Attwell, G. (2007). The personal learning environments-the future of e-learning? eLearning Papers, 2(1), 1-9.

Autor, D. H. y Price, B. (2003). The Changing Task Composition of the US Labor Market: An Update of Autor, Levy, and Murnane, 1-19. https://economics.mit.edu/files/9758

Bloom, B. S. (Ed.). (1956). Taxonomy of Educational Objectives: The Classification of Educational Goals. David McKay Company.

Brown, T. (2009). Change by Design: How Design Thinking Transforms Organizations and Inspires Innovation. Harper Collings Publishers.

CEOE. (2016). Plan digital 2020: la digitalización de la sociedad española. http://conteni dos.ceoe.es/CEOE/var/pool/pdf/publica tions_docs-file-334-plan-digital-2020-ladigitalizacion-de-la-sociedad-espanola.pdf

Docplayer. (2017). Informe sobre el progreso digital en Europa (EDPR) 2017: perfil de España. https://docplayer.es/66723595-In forme-sobre-el-progreso-digital-eneuropa-edpr-2017-perfil-de-espana.html

Grundmann, U. y Arnheim. R. (2001). The intelligence of vision: an interview with Rudolf Arnheim. Cabinet Magazine, 2. http://cabi netmagazine.org/issues/2/grundmann_ arnheim.php

Interempresas. (2019). El informe Eurydice: análisis de la educación digital en el curso académico 2018/2019 en los 38 países del programa Erasmus+. https://www.interempresas.
net/Tecnologia-aulas/Articulos/256122Informe-Eurydice-analisis-educacion-digitalcurso-academico-2018-2019-38-paisesprograma.html

Lee, D. (2018). Design Thinking in the Classroom: Easy-to-Use Teaching Tools to Foster Creativity, Encourage Innovation and Unleash Potential in Every Student. Ulysses Press.

Ministerio de Educación y Formación Profesional. Las competencias clave en el sistema educativo español según la Orden ECD/65/2015, de 21 de enero, relaciones entre las competencias, los contenidos y evaluación de primaria, ESO y bachillerato. https://www.educacionyfp.gob.es/educa cion/mc/lomce/curriculo/competenciasclave/competencias-clave.html

Morin, E. (1999). Los siete saberes necesarios para la educación del futuro. Paidós Estudio.

Robinson, K. y Aronica, L. (2015). Escuelas creativas: la revolución que está transformando la educación. Editorial Grijalbo.

Rubio, A. (2014). La educación a distancia en España. http://www.Imi.ub.es/teeode/THE BOOK/files/spanish/html/6spain.htm

Spencer, J. y Juliani, A. J. (2016). Usign Design Thinking to Boost Creativity and Bring Out the Maker in Every Student. Dave Burgess Consulting, Inc.

Trujillo, F. (2020). El potencial de la educación virtual. El País. https://elpais.com/especia les/2020/coronavirus-covid-19/prediccio nes/el-potencial-de-la-educacion-virtual/

Szczepanska, J. (2017). Design Thinking Origin Story Plus Some of the People Who Made It All Happen. https://medium.com/ @szczpanks/design-thinking-where-itcame-from-and-the-type-of-people-whomade-it-all-happen-dc3a05411e53 


\section{¿Qué nos diferencia de otras Universidades online?}

La Universidad a Distancia de Madrid, UDIMA, está diseñada para cubrir las necesidades de las personas del siglo XXI: profesionales que demandan una titulación universitaria reconocida oficialmente y de prestigio, adaptada a Europa y en contacto con el mundo de la empresa, y que facilite, además, una buena inserción laboral o mejore la que ya se posee.

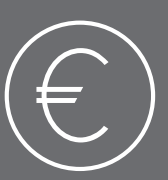

\section{Materiales incluidos}

El precio del crédito incluye todos los materiales necesarios para estudiar en la Universidad online más cercana. En la UDIMA siempre sabes lo que pagas. Sin sorpresas.
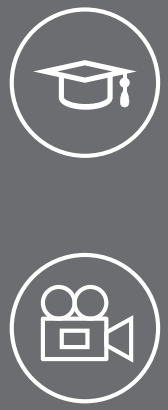

\section{Profesores especialistas}

Los profesores de la UDIMA no solo son expertos en la materia, sino también especialistas en la enseñanza online.

\section{Plató de grabación}

Contamos con un plató con las últimas tecnologías audiovisuales que nos permiten darte la máxima calidad en las clases en videoconferencia.
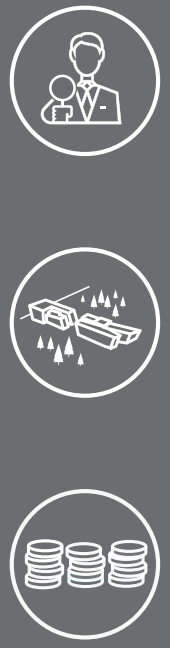

\section{Tutor personal}

Al inicio del Grado se te asignará un tutor personal que te acompañará todo el tiempo que estés con nosotros para que nunca te sientas solo.

\section{Campus propio}

Podrás venir a ver a los profesores a las instalaciones de Villalba. Nuestro campus ha ganado el prestigioso Premio Inmobiliario Internacional Asprima-SIMA.

\section{Pago fraccionado}

Para que el dinero no sea un impedimento, te ofrecemos la posibilidad de realizar el pago fraccionado o a través de financiación bancaria. Que estudiar sea tu única preocupación.

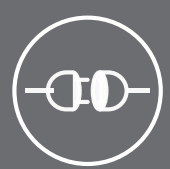

\section{Siempre conectados}

Nuestro compromiso es contestar en menos de $48 \mathrm{~h}$ a todas tus dudas, para que cumplir tus objetivos te sea más fácil. Siempre estaremos conectados.

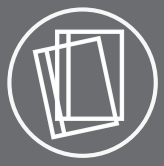

\section{Materiales adaptados}

Contamos con una Editorial propia que desarrolla los libros y carpetas especialmente diseñados para el aprendizaje online, que te llegarán a casa al principio de cada semestre.

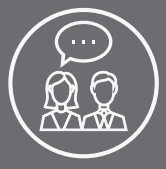

\section{Encuentros presenciales}

Realizamos talleres, conferencias y prácticas presenciales voluntarias que amplian el contenido de las asignaturas.

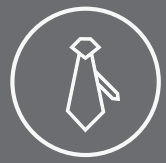

\section{Contacto con empresas}

Nuestra Bolsa de Trabajo y

Emprendedores te ofrece asesoría individualizada para que puedas potenciar tus cualidades y posicionarte como quieras en el mercado laboral.

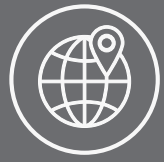

\section{Sedes de examen}

Estamos cerca de ti. Además de alrededor de toda España, contamos con sedes en Europa, Asia, África y América, con especial relevancia en Latinoamérica.

\section{Convocatoria en septiembre}

No es fácil compaginar el estudio con la vida personal y profesional. Por eso tenemos una convocatoria extra en septiembre. Tienes dos oportunidades al año de aprobar cada asignatura. 